This item was submitted to Loughborough's Research Repository by the author.

Items in Figshare are protected by copyright, with all rights reserved, unless otherwise indicated.

\title{
Laboratory assessment of cold weather clothing
}

PLEASE CITE THE PUBLISHED VERSION

PUBLISHER

(c) Woodhead Publishing Limited, UK

VERSION

AM (Accepted Manuscript)

LICENCE

CC BY-NC-ND 4.0

REPOSITORY RECORD

Havenith, George. 2019. "Laboratory Assessment of Cold Weather Clothing”. figshare. https://hdl.handle.net/2134/5899. 
This item was submitted to Loughborough's Institutional Repository (https://dspace.lboro.ac.uk/) by the author and is made available under the following Creative Commons Licence conditions.



For the full text of this licence, please go to: http://creativecommons.org/licenses/by-nc-nd/2.5/ 


\section{Woodhead Publishing}

\section{Textiles for cold weather apparel}

Part 4 - evaluation

\section{Chapter 17 Laboratory assessment of cold weather clothing}

Professor George Havenith

Department of Human Sciences

Loughborough University,

Ashby Road,

Loughborough, LE11 3TU,

United Kingdom

G.Havenith@lboro.ac.uk 
Contents



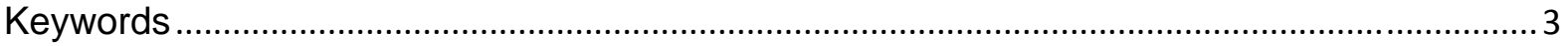

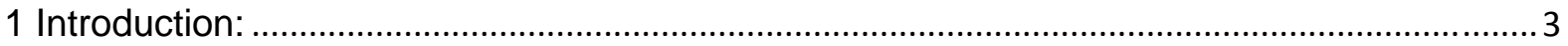

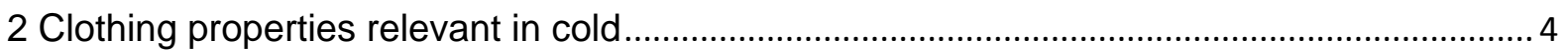

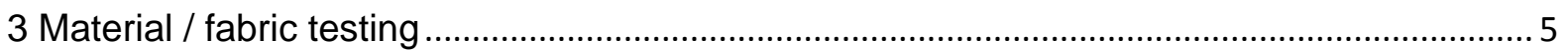

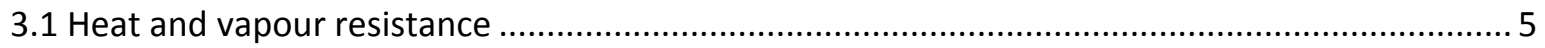

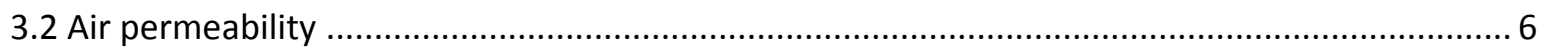

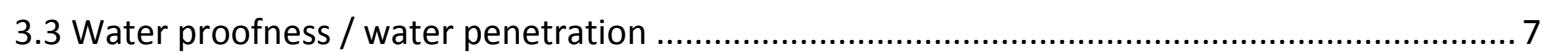

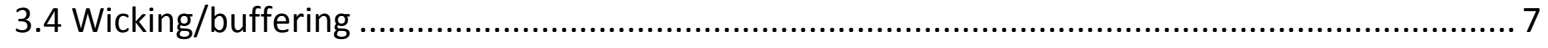

4 Garment and ensemble testing: physical apparatus .............................................................. 8

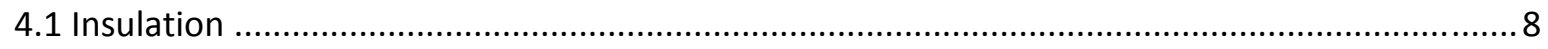



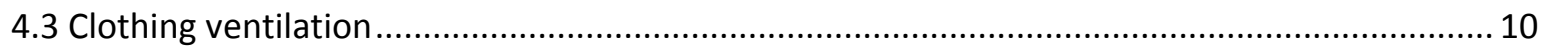

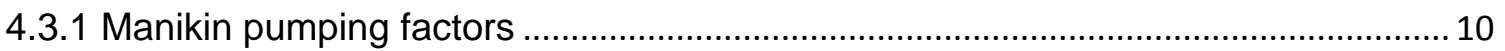

4.3.2 Prediction equation of ventilation effect of wind and movement ................................ 10

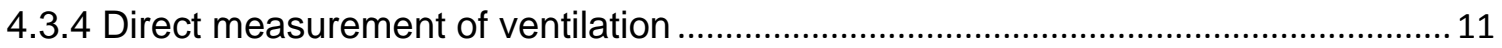



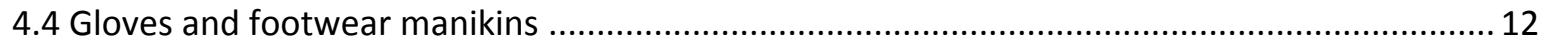

5 Garment and ensemble testing: human subjects ................................................................ 12



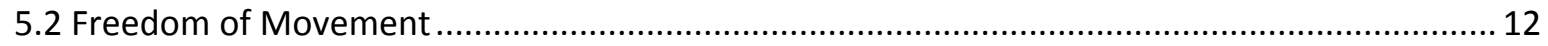



5.4 General considerations for testing on human participants .................................................. 14

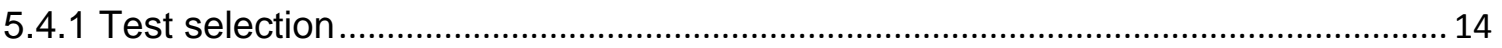

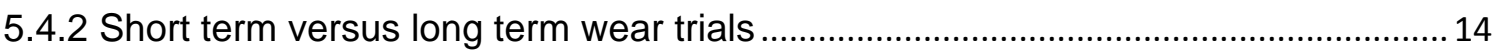

5.4.3 Test reproducibility: human subjects as evaluation tools............................................ 14

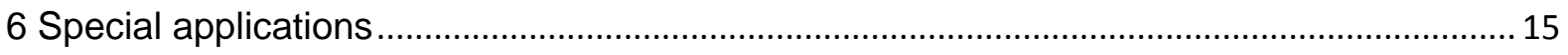



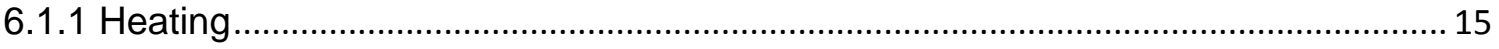










7 Future trends

\section{Chapter abstract}

An overview of laboratory tests for cold weather clothing is provided starting from physical measurements on fabrics, and physical measurements on whole garments using thermal manikins. This is extended to human wear trials and climatic chamber experimentation. Insulation and vapour resistance are considered the most relevant parameters followed by wind and water proofness and moisture absorption properties. The use of test participants in wear trials is considered regarding the information provided by such tests. Tests for innovative fabrics (heated, variable insulation, phase change materials) are discussed. Finally testing of sleeping bags is considered.

\section{Keywords}

Manikin, field test, wear trials, hot plate, sweat, insulation

\section{Introduction:}

Protecting people from the cold has had a long historical development. With the advancement of textile technology, a shift has taken place from using natural material solutions (fur, down) to manmade fibre and textile solutions or combinations of both. The wide spectre of material combinations that can be selected at present implies that during clothing development it is impossible to test all possible combinations as real garments in the field, and thus puts emphasis on preliminary evaluations at the fibre or textile level to narrow down the choices before going to prototype level. This requires a systematic approach in clothing development which was described by Goldman (1974) and Umbach (1983), presenting a staged approach to the problem. This approach is typically followed only in large development projects as found in the military, given the high cost of going through all the proposed stages. Developments initiated by clothing producers may only use one or two of the stages, and thus often limit themselves to small incremental improvements given the risks involved in making large changes to clothing concepts without extensive prototype evaluations.

The five stage approach advocated by Goldman and Umbach is in use widely in the clothing research community. It is schematically presented in Fig. 1, to which we have added stage zero: The approach should start with a detailed analysis of the task of the intended user of the clothing, thus defining the environmental conditions and activities for which the clothing needs to protect. Based on this 'wish list', a pre-selection of fabrics and materials takes place, which are tested for a number of physical properties (stage one), the most important being the thermal protection for the present application. Using the fabric characteristics, a 
prediction for the overall clothing characteristics can be made, which can be put into the now readily available thermal models that either analyse the balance of heat produced and lost by a hypothetical user (e.g. as done in the Required Clothing Index [EN ISO 11079, 2007]), or actually combine this heat balance approach with a physiological model of human thermoregulations which allows a prediction of the body's responses and the associated risks to the wearers health or comfort (stage two) (e.g. Lotens, 1993, Wissler and Havenith, 2009). Typically this then allows a reduction of the number of materials that could be expected to perform well to a manageable number. These can then be turned into complete garment or ensemble prototypes that can be exposed firstly to manikin (top end of stage two) and secondary to human wear-testing. This moves the testing from 'flat' apparatus to the human shape, increasing the complexity, time and cost of the testing per ensemble, but also increasing realism. In stage three, the clothing will be worn under defined conditions in a climatic chamber and detailed data of the wearer collected. The outcome of this testing may help narrow down the choices to two or three, which can then be tested in small or large scale field trials. Time required for these two stages as well as cost will increase over previous stages, while detail and precision will suffer. Nevertheless crucial information will be gained at this stage. The present chapter will focus on testing performed in stages one, two (manikin) and three describing tests providing objective data that can be used in development, evaluation and quality control of clothing.

\section{Clothing properties relevant in cold}

Depending on the definition of 'cold', cold protective clothing will be used in temperatures below five to ten degrees Celsius, but most likely well below zero degrees (EN standards 342-2004 and $14058-2004$ define cold as below $-5^{\circ} \mathrm{C}$ and cool as above $-5^{\circ} \mathrm{C}$ ). Hence, protection against cold, i.e. heat loss will be the predominant characteristic, with protection against water mainly relevant when temperatures above zero are expected in the work or where other liquids are present in the work environment.

On the other hand, due to fluctuations in the conditions (changing exercise levels, moving in and out of freezer rooms) not only the maximal cold protection is important, but also the range of temperatures in which the clothing can be used. When the workload increases, the clothing may become too warm, the wearer starts to sweat and evaporated sweat would need to be able to pass through the clothing to provide body cooling. Heat stress in the cold, due to protective clothing worn at higher work rates is not uncommon (Rintamaki and Rissanen, 2006). Hence the vapour permeability of the fabrics is important, and for the clothing as a whole the way it can be layered, opened for ventilation, and easily donned and doffed when conditions change. Apart from the actual heat stress, too much moisture accumulation may also affect cold protection once activity levels are reduced again. A large water content of the clothing system will affect the insulation and can cause the so called 'after chill', where accumulated moisture evaporates and substantially cools the person when activity is reduced. This increases the risk of hypothermia (reduced body temperature) and therefore is a risk factor.

The relevant measures for the above would therefore be:

- Heat resistance (convection/radiation)

- Vapour resistance/Permeability index 
- Water tightness

- Air permeability (affecting heat resistance in wind)

- Wicking

\section{Material / fabric testing}

\subsection{Heat and vapour resistance}

For comparison of different fabrics several tests on heat and vapour resistance are available and many are now defined in ISO, EN or ASTM standards. For heat resistance measurement, typically a guarded hot plate apparatus of some form is used, which measures the amount of heat lost through a sample at a certain temperature gradient between the plate and the environment. From this, insulation of the fabric can be calculated as:

$$
R_{\mathrm{ct}}=\frac{\bar{t}_{\text {plate }}-\bar{t}_{a}}{H_{D R Y}}-R_{0}
$$

with :

$$
\begin{aligned}
R_{c t} & \left.=\text { heat resistance of fabric sample (in } \mathrm{m}^{2} . \mathrm{K} \cdot \mathrm{W}^{-1}\right) ; \\
\bar{t}_{\text {plate }} & =\text { mean hot plate surface temperature }\left({ }^{\circ} \mathrm{C}\right) ; \\
\overline{t_{\mathrm{a}}} & =\text { ambient temperature }\left({ }^{\circ} \mathrm{C}\right) ; \\
H_{D R Y} & =\text { dry heat loss per square metre of plate area }\left(\mathrm{W} \cdot \mathrm{m}^{-2}\right) ; \\
R_{0} & =\text { heat resistance measured without a sample present }\left(\mathrm{in} \mathrm{m}^{2} . \mathrm{K} \cdot \mathrm{W}^{-1}\right) .
\end{aligned}
$$

Several styles of equipment and different standards are in use for this. Examples are ISO 11092, CAN/CGSB-4.2 No. 70.1-94 (now withdrawn), CAN/CGSB 4.2 NO. 78.1-2001, ASTM D 1518-85, and BS 4745. The main principles of these tests are similar, though the design varies in that some clamp the fabric between a hot and a cold plate, others add an air layer between sample and cold plate, or use only a hot plate while the other side of the sample is exposed to ambient air. The method can influence results strongly. E.g. a sleeping bag material will perform worse under compression (though this may be relevant to test), while e.g. a highly air permeable fabric may be affected by air flows in the equipment.

Similarly, also a number of methods for determination of fabric vapour resistance are available. Examples are: BS7209, CAN/CGSB-4.2 No. 49 - 99, ASTM F1868-02, ASTM F2298, ASTM E 96 and ISO 11092. Test methods can vary dramatically in complexity and cost. For cold weather clothing, where fabrics may be quite thick, not all techniques may be suitable, due to compression, edge effects etc.

For the guarded hot plate (see Fig. 2), the fabric's vapour resistance is measured as:

$$
R_{\mathrm{et}}=\frac{p_{\text {plate }}-p_{a}}{H-H_{D R Y}}-R_{e t 0}
$$


with:

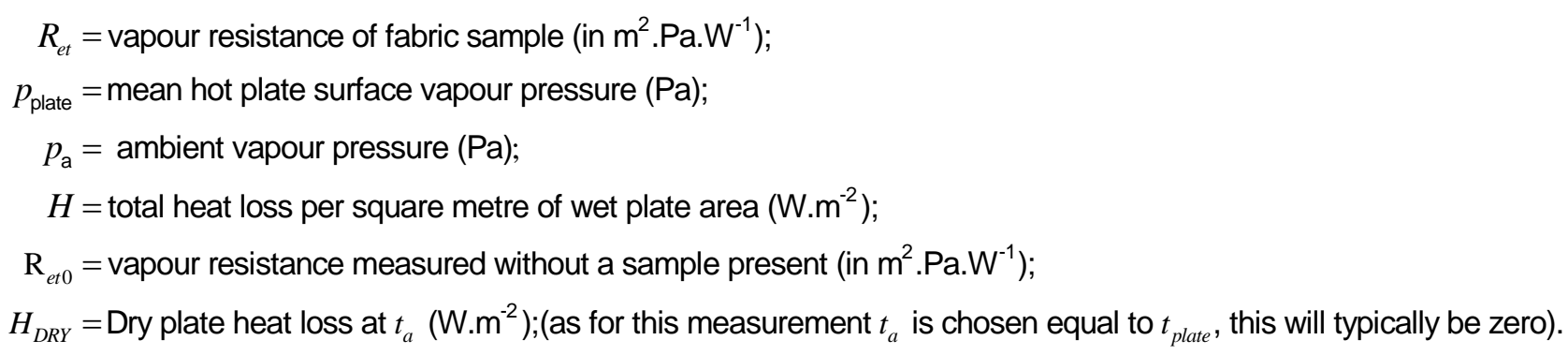

Other tests provide different results in terms of units, e.g. grams per 24 hours. Comparison of results obtained with different methods should be looked at critically (McCullough et al., 2003, Huang and Qian, 2008) as discrepancies exist due to the techniques used. Methods e.g. involving desiccants tend to create circumstances that do not exist in the real world. Most of such methods are mainly used for quality control purposes. For real life performance, the sweating guarded hot plate may be one of the better predictors, though cheaper alternatives may also provide useful information to the development process.

The results of the heat resistance measurements then need to be judged against the insulation required, while in relation to the vapour resistance one may work on the principle: the lower the better. However, when fabrics differ in heat resistance, they usually differ in thickness and this thickness will also increase vapour resistance. Comparing the vapour resistance per se may therefore not be meaningful and it is more relevant to compare the ratio between heat and vapour resistance (the higher the better). This is usually expressed as the water vapour permeability index:

$$
i_{m t}=S \cdot \frac{R_{\mathrm{ct}}}{R_{\mathrm{et}}}
$$

with :

$$
S=60 \mathrm{~Pa} \cdot \mathrm{K}^{-1}
$$

This number varies between zero (totally impermeable) and one (air) (though the typical upper limit is due to its definition around 0.5), and as mentioned before to avoid moisture accumulation the highest number is best here.

With some water vapour permeable membranes, moisture transfer can be affected by the humidity at the membrane and by the local temperature (Havenith et al., 2004). In such cases, measurements at actual ambient temperatures can be relevant.

\subsection{Air permeability}

When wind speed increases, a fabric's heat and vapour resistance may decrease in relation to its air permeability. This can be quantified via the fabric air permeability that can be determined e.g. by EN ISO 9237. For cold protection, a low number is better in order to provide wind protection. For cold protective clothing, air penetration can be beneficial when heavy work is performed in the clothing (inducing heat stress). In that case, design features like variable ventilation openings, allow the microclimate ventilation to be increased. We will return to this later in the garment testing phase. 


\subsection{Water proofness / water penetration}

The materials resistance against water penetration can be measured e.g. by EN 20811 (1992). The higher the number, the better. New tests have been developed that test the garment as a whole (EN 14360, 2004), which include the effect of design features. It should be noted that for fabrics meant to be used in extreme cold (e.g. cold storage at $-40^{\circ} \mathrm{C}$ ) no liquid will be present, and as waterproofing (coating, membranes) typically reduces vapour permeability, the criterion for this test should be adapted to the application range of the fabric. IF liquid protection is not required, leaving out the waterproof layer/membrane/coating will increase the temperature range of application of the clothing, as the vapour resistance decreases. Nevertheless, such layers do also contribute to wind-proofness of the clothing and a balance may need to be struck here. A good example here are e.g. wind-stopper ${ }^{\circledR}$ fabrics where wind proofness is increased with a limited penalty for vapour permeability.

\subsection{Wicking/buffering}

Where the protective clothing ensemble includes underwear or other next to skin materials, wear comfort can be affected by the wicking ability of the fabrics. Discomfort is linked to the presence of liquid on the skin, and the removal of this, either by optimised evaporation or by wicking the moisture away from the skin is thus a relevant factor. Wicking fabrics can benefit comfort and cooling in two ways. When the person starts to sweat in their cold protective garments, this sweat can be absorbed by the fabric, spread over a bigger area and thus facilitate evaporation. Also, by removing the liquid from the skin and transporting it away from the skin-fabric interface, clinging of clothing with its associated discomfort is reduced. Also this reduces 'after-chill', the continued cooling of sweat on the skin that occurs after exercise if moisture remains on or close to the skin and promotes fast drying of fabrics.

When the person is very active, and thus produces a lot of sweat, the comfort effect related to wicking ability is limited, as with saturation of the clothing the spreading becomes less relevant, and comfort is low in all fabric types.

The wicking/buffering effect can be measured on the sweating guarded hot plate, allowing the liquid water to touch the fabric and looking at overall moisture loss, or by measuring the microclimate response to a short sweating burst (Mecheels and Umbach, 1976). Other methods look at the wicking of liquid into vertically hanging strips of fabric after fixed time periods (BS 3424; 1996 and DIN 53924), or looking at the dispersion of a drop of liquid on a fabric (visual test). Trying to make this more objective, electrical conductivity of fabrics has been used to define the water absorption speed (Van Langenhove and Kiekens, 2001)

\subsection{Thermal character}

One parameter that may have an important role in the buying behaviour of consumers is the initial sensation when the garment touches the skin (the feeling when the garment is touched/gripped in the shop). This may not affect the functional performance of the garments and hence it is only briefly mentioned here. Examples of instruments for assessing parameters related to this sensation can be found in the Kawabata system and e.g. in the Alambeta tester, the latter looking at the 'warm-cool feeling' in the first two seconds of skin contact. 


\section{Garment and ensemble testing: physical apparatus}

As the step from fabric testing to human subject lab and wear trials is quite big, a need was present to have an intermediate step to test complete garments and ensembles on a physical test apparatus, providing the precision and repeatability that is limited in human wear trials, but still incorporating all effects that differentiate garments from fabrics like fit, drape, ventilation etc. This method was developed from the 1940's onwards in the form of thermal manikins, which are now available in a variety of sizes (baby-adult), shapes (malefemale) and technologies (metal, resin shells, water filled fabric shells etc.), of which many now can produce 'sweat' (uniformly wet skin or regional variation in sweat output). Manikins tend to be regulated in a number of individual body zones, so that local insulation can be studied in addition to whole body insulation. This allows a better analysis of 'cold spots' in the clothing design. Most current manikins have between 16 and 30 body zones that can be individually assessed. Measurements are typically performed with the manikin static, as well as with the manikin performing walking movements. Also measurements without wind (static) and with wind can be performed. In this way, effects of pumping, ventilation and air penetration can be performed which is crucial for cold weather garment assessment.

\subsection{Insulation}

The principle of the manikin (see Fig. 3) is the same of that of the (sweating) hot plate, be it that it is now in a human shape (EN ISO 9920, ASTM F1291 and F2370, EN ISO 15831). For dry heat insulation (the prime parameter for cold protection) the manikin surface is controlled at a set temperature and the energy (heat) required keeping this set temperature is then directly related to the manikin's insulation:

$$
I_{\mathrm{T}}=\frac{\overline{t_{s k}}-t_{a}}{H_{s k}}=\frac{\sum \alpha_{i} \cdot t_{i}-t_{a}}{\sum\left(\alpha_{i} \cdot H_{i}\right)}=\frac{\sum \alpha_{i} \cdot\left(t_{i}-t_{a}\right)}{\sum\left(\alpha_{i} \cdot H_{i}\right)}
$$

with $\alpha_{\mathrm{i}}=\frac{\text { surface area of segment } i}{\text { total surface area of manikin }}$

$I_{T}=$ insulation of complete ensemble including enclosed and surface air layers (in $\mathrm{m}^{2} \cdot \mathrm{K} \cdot \mathrm{W}^{-1}$ );

$\overline{t_{s k}}=$ average skin temperature $\left({ }^{\circ} \mathrm{C}\right)$;

$t_{i}=$ temperature of segment $i\left({ }^{\circ} \mathrm{C}\right)$;

$t_{a}=$ ambient temperature $\left({ }^{\circ} \mathrm{C}\right.$ ); (if radiation is present, this is replaced by operative temperature);

$H_{i}=$ heat loss of segment $i(\mathrm{~W})$.

If the measurement is performed with a uniform skin temperature over the body, i.e. $t_{i}=t_{s k}=$ constant, then equation [4] becomes more simple and follows the so-called parallel method:

$$
I_{\mathrm{T}}=\frac{\overline{t_{\mathrm{sk}}}-t_{a}}{\sum\left(\alpha_{i} \cdot H_{i}\right)}
$$

For other skin temperature settings (e.g. the comfort mode where skin temperature differs over the body) equation [4] is the only correct calculation. In the literature, another calculation method ('serial') can be found, but the required boundary conditions for this (uniform heat flux over the body) are almost never met. 


\subsection{Vapour resistance}

For the measurement of vapour resistance, usually the ambient temperature is set equal to skin temperature to eliminate any DRY heat loss (Isothermal conditions). Then the calculation becomes:

$$
R_{\mathrm{e}, \mathrm{T}}=\frac{\overline{p_{s k}}-p_{a}}{H_{s k}}=\frac{\sum \alpha_{i} \cdot p_{i}-p_{a}}{\sum\left(\alpha_{i} \cdot H_{i}\right)}=\frac{\sum \alpha_{i} \cdot\left(p_{i}-p_{a}\right)}{\sum\left(\alpha_{i} \cdot H_{i}\right)}
$$

If the measurement is performed with a uniform skin vapour pressure over the body, i.e. $p_{i}=$ $\mathrm{p}_{\mathrm{sk}}=$ constant, then equation [6] becomes :

$$
R_{\mathrm{e}, \mathrm{T}}=\frac{\overline{p_{\mathrm{sk}}}-p_{a}}{\sum\left(\alpha_{i} \cdot H_{i}\right)}
$$

If, instead of measuring heat flux, a measurement of mass loss due to sweating is performed, no regional resistances can be calculated. The calculation becomes:

$$
R_{\mathrm{e}, \mathrm{T}}=\frac{\overline{p_{\mathrm{sk}}}-p_{a}}{H_{\mathrm{sk}}}=\frac{\overline{p_{\mathrm{sk}}}-p_{a}}{\operatorname{massloss} \cdot \lambda}
$$

$R_{e, T}=$ vapour resistance of complete ensemble including enclosed and surface air layers (in $\mathrm{m}^{2}$.Pa. $\mathrm{W}^{-1}$ );

$\overline{p_{s k}}=$ average skin vapour pressure $(\mathrm{Pa})$;

$p_{i}=$ vapour pressure of segment $i(\mathrm{~Pa})$;

$p_{a}=$ ambient vapour pressure $(\mathrm{Pa})$;

$H_{i}=$ heat loss of segment $i(W)$;

mass loss $=$ amount of moisture evaporated from ensemble per unit of manikin surface area per second $\left(\mathrm{g} \cdot \mathrm{m}^{-2} \cdot \mathrm{sec}^{-1}\right)$;

$\lambda=$ latent heat of evaporation at skin temperature (approx. $2430{\mathrm{~J} . \mathrm{g}^{-1}}^{\text {) }}$.

One of the main problems with vapour resistance measurements on the various manikin types is to ensure a uniform vapour pressure on the skin, and to measure this. In manikins that have a pre-wetted skin before dressing, this is deducted from the skin temperature (assuming saturation). In manikins with uneven sweat distribution (e.g. simulating certain scenarios with realistic sweat distributions (Havenith et al., 2008a), this is problematic, especially in terms of ensuring that a segment is evenly wetted over its surface. In most manikins, the wetted surface lies on top of the temperature controlled surface, which may introduce additional errors as the wet surface's temperature will then be lower due to the evaporative cooling, the more evaporation takes place, and if not taking this into account an error is made.

If measurements are not done in isothermal conditions, the heat flows need to be corrected for DRY heat losses. Also, the cooler the air in which the measurement is done, the higher the likelihood of condensation taking place in the clothing. It has been shown, that this has a major effect on heat loss, especially in cold weather garments with limited vapour 
permeability (Havenith et al., 2008 ${ }^{\mathrm{b}}$ ) and thus non isothermal measurements can provide highly relevant information for cold weather garments. This aspect can only be measured if the actual heat losses are measured directly. Manikins that deduct heat loss from mass loss may make substantial errors here, as this condensation heat loss is not included in the mass loss calculation.

Before the advance of sweating manikins, vapour resistance was often deduced from the combination of dry insulation data from the manikin and fabric vapour resistance data from the sweating hot plate (Mecheels and Umbach, 1976). At the moment, mostly direct measurements are performed.

A more in depth discussion on manikin measurements is provided in Chapter 18.

\subsection{Clothing ventilation}

Ventilation of the clothing microclimate is particularly important in cold weather clothing. For cold protection, high insulation values in extreme conditions require windproof clothing that can be made rather airtight at openings (collars, zips etc.) too. This however means that when activity levels increase and more heat is generated than lost, heat stress may develop and the clothing needs to be adaptable to the higher heat loss requirement. A high permeability index is the starting point for this allowing sweat evaporation, but given the tightly woven textiles mostly with coatings or membranes used as outer layer to ensure wind proofness, this is quite limited in scope. The alternative is incorporation of ventilation openings in the clothing that can be adjusted to the need for microclimate ventilation (Havenith, 2003). This provides a direct convective pathway from the skin to the environment, without hindrance in terms of fabric heat and vapour resistances (see Fig.4).

\subsubsection{Manikin pumping factors}

In order to evaluate the effectivity of microclimate ventilation this needs to be measured either directly (tracer gas methods) or indirectly (manikin heat loss). Umbach (1976) and Mecheels (1983) describe a series of manikin measurements from which they deduct the clothing ventilation. By measuring heat loss from the manikin dressed in the test clothing while static, while walking with all openings tightly closed, and while walking with all openings maximally open, they were able to break down the manikin heat loss into a maximal value (resting) and an active value with and without ventilation. Dry ventilation can be teased out as:

$$
\text { Ventilation conduction }=\frac{1}{I_{\text {ventilation }}}=\frac{1}{I_{T}(\text { walking, open })}-\frac{1}{I_{T}(\text { walking, } \text { closed })}
$$

It should be noted that in their approach wind speed was not changed (they focus mainly on the pumping effect of walking), but this could easily be added. They applied the same approach to evaporative ventilation heat loss.

\subsubsection{Prediction equation of ventilation effect of wind and movement}

The effect of wind and movement on clothing insulation was extensively studied by Nilsson et al. and by Havenith et al., who integrated and summarised their findings producing prediction equations for the size of these effects for different clothing types including cold weather (Havenith and Nilsson, 2004, 2005). For standard cold weather clothing they provide the following equation: 


$$
I_{\mathrm{T}, \mathrm{r}}=\left[e^{\left\{\left[-0.0512^{*}\left(V_{a r}-0.4\right)+0.794 * 10^{-3 *}\left(V_{a r}-0.4\right)^{2}-0.0639 * W\right] * p^{0.1434}\right\}}\right] \cdot I_{\mathrm{T}, \text { static }}
$$

with: $I_{\mathrm{T}, \text { static }}=$ Insulation measured on static manikin at $0.4 \mathrm{~m} . \mathrm{s}^{-1}$ wind speed; $I_{\mathrm{T}, \mathrm{r}}=$ resultant insulation including effects of ventilation (wind and walking); $0<$ walk $<1.2 \mathrm{~m} . \mathrm{s}^{-1}$ and $0.4<$ wind $<18 \mathrm{~m} . \mathrm{s}^{-1}$ and $1<\mathrm{p}<1000 \mathrm{Im}^{-2} \mathrm{~s}^{-1} ; \mathrm{r}^{2}=0.968$; SEE=0.048; with $\mathrm{p}=$ clothing air permeability (typical permeability values that can be used are 1 for garments with impermeable membranes; 50 for densely woven workwear and 1000 for highly permeable garments (e.g. fleece without membrane)).

For the lower area of the wind range better results were obtained in a separate analysis:

$$
\left.I_{\mathrm{T}, \mathrm{r}}=e^{\left(\left(-0.0881^{*}\left(V_{a r}-0.4\right)+0.0779 *\left(V_{a r}-0.4\right)^{2}-0.0317^{*}(w)\right)^{*}\right.} p^{0.2648}\right) \cdot I_{\mathrm{T}, \text { static }}
$$

with $\mathrm{r}^{2}=0.931$, SEE $=0.023 ; 0<$ walk $<1.2 \mathrm{~m} . \mathrm{s}^{-1}$ and $0.4<$ wind $<1 \mathrm{~m} . \mathrm{s}^{-1}$ and $1<\mathrm{p}<1000 \mathrm{Im}^{-2} \mathrm{~s}^{-}$ 1 .

Though Havenith et al. did produce similar equations for vapour resistance (latest version published in ISO 9920), no such equation was developed specifically for cold weather clothing.

\subsubsection{Direct measurement of ventilation}

As ventilation is about the exchange of microclimate air with 'fresh' environmental air, this can be measured using tracer gasses that, mixed in the microclimate air, will follow such air movement. Two methods for this have been developed that can be used on human subjects, but also on manikins (the manikin does not have to be a thermal one, though the controlled surface temperature would add more realism in terms of convection patterns).

The first method, originally developed by Birnbaum and Crockford (1978) blows in a gas (usually Nitrogen) under the clothing that displaces the oxygen present in the microclimate. When this gas supply is switched off, oxygen from the ambient air re-enters the clothing by ventilation and diffusion, and the time constant of the oxygen concentration change in the microclimate can be used to quantify the ventilation (Ueda et al. 2002). The number produced is the number of air exchanges that take place per unit of time. To translate this into ventilation (in volume units), this needs to be multiplied with the microclimate volume. The latter was traditionally difficult to assess, but with 3D scanning equipment this can now be done more reliably (Daanen et al., 2002).

The second method, developed by Lotens and Havenith (1988), uses a diluted tracer gas (usually Argon), that is blown into the microclimate in a continuous stream, and the steady state microclimate concentration is sampled, from which the ventilation (volume per time) can be calculated directly (Havenith et al., 1990, 2003). This method has been shown to be repeatable and accurate, if the tracer gas is distributed equally over the microclimate regions. Efforts are under way to measure this ventilation for different regions of the body separately (Ueda et al., 2006). 


\subsubsection{Infra-red image analysis}

Especially for cold weather clothing, the analysis of cold spots is important to identify design flaws. As mentioned above, this can be done on manikins that have a detailed measurement system with many individual zones.

An alternative method is the use of Infra-red imaging. With the manikin at a fixed surface temperature or the clothing worn by test subjects, and the clothing worn long enough to create a stable temperature distribution, Infra-red analysis of the clothing surface temperature may reveal local 'hot spots' which are manifests of location where body heat finds little resistance to come to the surface, and which may be experienced as cold spots by the wearer. Clothing fit can play an important role here as where clothing gets tight, insulation may be lost as the insulative materials get squashed. Also seams that leak heat can be easily identified in this way.

\subsection{Gloves and footwear manikins}

For the special applications of gloves and footwear, often equipment is used functioning as a manikin, but only consisting of an arm with a hand for the glove testing and a leg with a foot for shoes (Kuklane et al., 1997, 1999). These devices usually have more detail in these areas than whole body manikins have, though this is not a requirement for EN 511 (2006) which describes glove testing for cold environments.

\section{Garment and ensemble testing: human subjects}

As discussed by many authors (Goldman 1988, Lotens 1988, Umbach 1983, Havenith and Heus, 2004), wear trials of garments provide invaluable information that cannot be gained from lab tests on test equipment. Apart from wear trials in the field, many laboratories carry out laboratory trials with humans in climatic chambers, where most outdoor conditions can be set up accurately and more importantly: reproducibly.

Keeping the conditions constant, it is possible to compare a number of garments on the same test subjects and get a good comparison of their properties in real use.

\subsection{Heat and vapour resistance}

Using indirect calorimetry, it is possible to measure most components of human heat exchange with the environment. Such an analysis (see Holmér and Elnas 1981, Havenith, 1990, 2002 for details) allows the calculation of the effective heat and vapour resistance of the clothing, including all effects of movement and wind. Unfortunately this is a very time consuming measurement, and therefore costly. Also the repeatability is lower than that of manikin testing, and the measurement needs to be repeated on several test participants to become reliable and allow statistical comparisons (Havenith and Heus, 2004).

\subsection{Freedom of Movement}

The freedom of movement test (Havenith and Heus, 2004) takes account of the design and fit of the garments in relation to their effect on task performance. For this purpose, the participants need to perform task-related activities where possible, but where this e.g. requires equipment that cannot be brought into the lab, one can consider 'simplified' tasks instead that nevertheless have a relation with actual task performance. E.g. for rescue 
workers who need to be able to move fast and freely in their cold protective clothing, an obstacle course can be devised that challenges the clothing design in this respect. Movements that will 'stretch' the garments, like bending, kneeling, crawling can be incorporated, and the time needed to finish such an obstacle course is a good indication for the clothing's performance in this respect. The clothing's performance is measured in relation to the time to do the obstacle course in a training suit. In addition various small tests (time needed for donning, $80 \mathrm{~m}$ sprint, running in 8 shaped pattern underneath a lowered bar, sit and reach and stand and reach test, Sargeant's jump can be added to evaluate the way in which the clothing hampers the movement. Tests follow a within-subject design, in which each participant wears all garments and a control. Tests need to be spread out in time sufficiently to avoid them influencing each other (fatigue, time of day, heat/cold accumulation), and performed in a balance order over the different participants to avoid order effects.

Such tests should preferably be validated for the profession studied (Lotens, 1982; Havenith and Heus, 2004).

In addition to the performance measurements, questionnaires taken during these tests provide essential information on the ergonomic properties of the clothing.

For clothing for extreme cold, the clothing weight together with the stiffness, friction between multiple layers, fit etc. may cause substantial performance loss. The can be measured with timed trials as discussed here, but in extreme cases it may be relevant to quantify the extra energy usage when wearing the clothing. This is done via a measurement of oxygen consumption in fixed work trials (walking, obstacle course etc). An example of this is given in Fig. 5, where the effect on energy consumption was measured for two historical protective ensembles: replica clothing as worn by Robert Falcon Scott and Roald Amundsen on their respective 1911/1912 journeys to the south pole and for a modern day expedition ensemble used for the same type of expedition. The figure shows the dramatic difference in energy consumption increase for the different ensembles compared to a track suit control and indicates the expected differences in progress speed, nutritional requirements and fatigue for different clothing designs. Recent studies have shown that many cold protective garments cause increases in energy consumption of the wearer in the order of 8 to 17\% (Dorman and Havenith, 2006. 2009) with a concomitant increase in heat production during these tasks.

\subsection{Ergonomical Design Assessment}

As the clothing is only worn for brief periods during the tests described above, not all ergonomic problems may surface. Hence, an assessment by an ergonomist and/or expert on the profession can provide additional info.

When all the clothing and equipment worn during a certain task is combined the clothing still should be functioning properly and provide the basic functions (protection, storage, etc.) to the wearer. For this aspect an expert panel (ergonomics and topic specialist) assesses the clothing. While the clothing is worn by participants of different statures and builds, and importantly also by panel members, the clothing is evaluated for freedom of movement, proper design (overlap between jacket and trousers, arm length), compatibility with other equipment (e.g. gloves, boots). The clothing performance is measured using consumer evaluation type tables (scores: much better, better, equal to, lower/worse etc. than average or than old suit or a reference suit) (Havenith and Heus, 2004). 


\subsection{General considerations for testing on human participants}

\subsubsection{Test selection}

The test battery described in Havenith and Heus (2004) represents a series of tests that in the past have been shown to discriminate between clothing ensembles in a meaningful manner. That test battery is not exhaustive, however. With this testing one should keep in mind that a large investment of time and cost is involved, and therefore one should always make a selection of tests that is most relevant to the specific clothing that is under investigation. For this reason, it is essential that the experimenter tries to anticipate what kind of results he or she may get from a test and actually consider the usability of such results in the evaluation. To give an example about selecting the conditions: when one wants to test whether clothing has sufficient 'breathability' (i.e. high vapour permeability) one should allow vapour transport in the selection of the climate. If one would test in an environment with vapour pressure equal to the skin's, one would never find any differences between garments due to the absence of a vapour pressure gradient and results could not be interpreted for other conditions. The test then is superfluous as results could have been predicted. Trying to differentiate between breathable membranes for fire-fighter clothing in a firehouse test at extreme temperatures, where vapour pressure of the environment will be higher than that on the skin, and where thus no vapour will leave the skin is an example of choosing the wrong test conditions. On the other hand such conditions are good for testing the heat protection of suits; however that is a different question.

Another point related to test selection is that the tester or the representative for the profession should in advance consider what they would do with the results and what priority they would give them. E.g. testing suits at a low temperature and vapour pressure will generally give the opposite ranking to testing these suits at very high temperatures and vapour pressures due to their insulative properties. If one isn't able to give priority to one of these conditions for the task performance, there is no use in doing the tests as no overall conclusions could be drawn.

\subsubsection{Short term versus long term wear trials}

The tests described here are short-term tests. Long-term user trials (Behman, 1988, Lotens, 1988) would provide additional information on ageing and wear and tear of materials and haberdashery. Considering the cost implications of such tests, they are only feasible in very large procurement projects (e.g. military), and goes beyond the scope of the present chapter. In such wear trials a lot of information is gathered by questionnaires and regular inspections of the clothing. In the tests described here, part of that information can be collected by questionnaires filled in by the participants after each test. The actual test procedures, apart from providing objective data, have an important second function in this respect. This is to get the participants in the test clothing through task-related activities that will bring to light shortcomings in wearability, compatibility, design, sizing, production quality, quality of zippers, fasteners, seems, etc.

\subsubsection{Test reproducibility: human subjects as evaluation tools}

Tests discussed in sections two to four above are geared towards precise and reproducible results. In the tests proposed in section 5 , measurements are performed using human subjects as 'evaluation tools'. This implies that the experimenter will have to expect human 
variability to influence the results. While inter-participant variability is desirable in order to evaluate the cold protective clothing for use by different populations (e.g. sizing effect), intraparticipant variation (differences between days for the same participant in the same condition etc.) is undesirable and efforts should be made to minimise this. Pre-test conditioning of clothing and participants are thus important, as is the participants' motivation level, which needs to remain high. Though this variability will not produce bias in the data if the experimental design is properly balanced, it will increase noise levels in the data. Experience shows that the tests described here can discriminate well between different clothing ensembles for various cold protective clothing types, and that they are very sensitive in exposing typical weak spots in the clothing design or manufacturing process.

\section{Special applications}

\subsection{Smart / innovative fabrics}

Several types of smart or innovative fabrics can be found in cold weather clothing. The main types at this moment are fabrics with integrated heating, fabrics/garments with variable insulation, and fabrics incorporating phase change materials.

\subsubsection{Heating}

Actively heated garments, using a power supply and woven in or intrinsically conductive fibres can be used to generate extra heat and improve wearer comfort. Used in e.g. gloves, they can extend allowable exposure time of workers with maintained manual dexterity substantially. Testing of such equipment in the lab situation can be performed on thermal manikins, or for gloves and shoes on special thermally controlled manikin body sections. These would have to be tested in realistic climates to be able to discriminate between the passive and active insulation parameters, and to see how much of the power usage actually benefits the wearer.

\subsubsection{Variable insulation}

Garments with variable insulation, which may be changed automatically using controllers are mostly based on changing the thickness of the enclosed air layer in the garment, e.g. by spacer fabrics in combination with shape memory materials pushing the fabric layers 'open' when cooled, or by inflating bladders integrated in the garment. These types of garments can easily be evaluated on a standard manikin by measurement of the insulation provided in the different states the garment can take. Apart from Dry insulation, in these cases it is important to evaluate vapour resistance as well, as the introduction of systems described here (e.g. air bladders) may have a penalty in terms of increased vapour resistance.

\subsubsection{Phase Change Materials}

One of the more recent additions to cold weather clothing systems is that of Phase Change Materials (PCM). The classical phase change material is water, which freezes (changes phase) at zero ${ }^{\circ} \mathrm{C}$, and while freezing releases a vast amount of heat, i.e. slows down the temperature drop. The main problem is that zero ${ }^{\circ} \mathrm{C}$ is not often reached inside clothing, certainly not close to the body and thus water is outside the useful range for a PCM. Modern PCM's, consisting of different molecular chain length paraffin waxes, can be produced with a range of $P C$ temperatures. Most are set between 20 and $35^{\circ} \mathrm{C}$. The idea is that when a sudden temperature drop or increase occurs, the micro-encapsulated PCM's are pushed through their phase change and thus will buffer (slow down) the sudden drop so the wearer 
remains more comfortable for longer. When heated back up, the phase change in the other direction will buffer any sudden temperature increases.

Micro-encapsulated PCM's are typically integrated into the fabric or the fibre or added as a coating or integrated in a foam. This implies that only small amounts are present (mostly less than 80 grams per square meter) and only a small amount of heat can be absorbed or released in most normal garments. The effect is measurable on fabric samples (Bo-an et al., 2004 ${ }^{\mathrm{a}, \mathrm{b}}$ ), and e.g. ASTM standard D7024-04 (2004) is very much fine-tuned to demonstrate the effect. The presence of PCM's in garments is often noticed by consumers when gripping/feeling the fabric, though this initial grip is rather different in terms of effect than what happens during actual wear. Overall there is little evidence for a positive impact on people wearing these garments (Shim and McCullough, 2000). Most studies suggesting an effect have either measured only the fabrics or have methodological problems, in that their PCM garment differs from their control in several aspects, not just the presence of PCM. PCM's tend to make the garment heavier (increasing metabolic rate of the wearer and thus heat generation) and reduce the vapour permeability (Pause, 2000) thereby reducing evaporative heat loss. Shim and McCullough (2000) e.g. observed more moisture accumulation in the garments with PCM; i.e. a negative effect.

Another problem with PCM's is that their PC temperature needs to be fine tuned to the conditions in order to be activated in use. This means that if the climate gets e.g. $10^{\circ} \mathrm{C}$ colder, the PCM's may go out of their active range and not be activated.

An impact of PCM was demonstrated by Reinertsen et al. (2008), but in this case the PCM was present in large amounts (several pounds) in a situation similar to an ice vest. In this case enough heat storage capacity was present and the PCM allows a more comfortable action temperature of the substance than in the case of water/ice.

In terms of lab testing, as mentioned before ASTM D 7024 (2004) provides a methodology that is geared towards high sensitivity for PCM effects. Its test conditions are modified for each specific PCM fabric to ensure it catches the precise PCM temperature change for the sample. Also heat capacities of the equipment are chosen extremely low in order to detect the effects. This test may not have much relevance for the real life situation, however. A sample with good test results in this test may not be activated at all during actual use in garments, as it may not be placed in the precise location where it would reach the activation temperature. Several attempts have been made to use manikins for such testing, either by moving the manikin between climates (Shim and McCullough, 2000) or by changing the power to the manikin in analogy to the ASTM test (Havenith, unpublished data). In both instances it has been difficult to see effects, and those observed showed only small changes in heat loss (below 10W) which may in part have been due to other differences between the PCM and control clothing (difference in conductivity due to PCM). Effects lasted around 15 minutes in the changing climates test. In the changing power test, results showed slightly reduced amplitude of manikin surface temperature with $\mathrm{PCM}$, which supports the positive PCM effect, but the mean surface temperature with PCM was lower suggesting a lower insulation with PCM during the transient, i.e. a negative effect.

Though benefits for wear situations with a single phase change (stepping out into the cold) may be unproven, positive effects may be expected where multiple changes take place in 
succession, e.g. for forklift truck drivers driving in and out of cold stores. Test methods with real life value for this are not yet fully developed.

\subsection{Sleeping bags}

Sleeping bags may be seen as an ultimate form of cold weather clothing. Especially expedition and mountaineering bags aim to provide maximal cold protection at minimal weight. In the assessment of sleeping bag performance, the main problem is the translation of the physical data to a realistic range of use of the sleeping bags. This is mostly due to the immense variation between individual users in their experience when using a bag, with experienced mountaineers e.g. tolerating some level of cold stress while still sleeping on one hand and the common anecdotal response of female recreational users suffering severe discomfort in the same bag at much higher temperatures at the other.

The first step in sleeping bag assessment is the determination of the physical parameters: heat and vapour resistance. Heat resistance for cold protection, vapour resistance for looking at the higher 'warm tolerance' threshold for use. Moisture accumulation during prolonged use can also be an important parameter to determine as moisture will affect the insulation (Havenith, 1989, 2002).

It is important to define a number of factors when measuring/calculating sleeping bag insulation:

- The clothing worn while sleeping

- The model of the bag

- The floor insulation

- The insulation of any mattress used

As these will influence the range of use of the bags.

\subsubsection{Thickness}

The dry insulation of sleeping bags is strongly linked to its thickness. .

Fig. 6 shows an overview of flat plate measurements of sleeping bag fillings, showing that thickness is a very good predictor of insulation of a bag filling (assuming appropriate design and manufacture). Thickness measurements are easy and fast.

A simple approach to predicting sleeping bag performance or for quality control can therefore be a measurement of the thickness of the filling or the bag, ideally in two conditions: uncompressed and compressed (Havenith, 1989). Uncompressed represents the upper side of the bag, which is measured with a low pressure (typically 10 to $20 \mathrm{~Pa}$ for reproducibility, with lower values often used for down bags). The compressed side represents that for the lower section of the bag underneath the user and this is thus compressed to a pressure equivalent to that of a person (1500 Pa). This measurement also works well to look at the washing behaviour of bags, which is especially important for nonpersonal bags that are washed regularly (Havenith, 1989, see Fig. 7.

Fig. 6).

A first order approximation model of the sleeping bag insulation based on these thicknesses was developed by Havenith (1994), based on typical specific insulation values of sleeping 
bag fillings compressed $\left(30 \mathrm{mKW}^{-1}\right)$ and uncompressed $\left(20 \mathrm{mKW}^{-1}\right)$ and on the covered and exposed body areas (exposed head: $7 \%$ of body area for blanket model bag; $3 \%$ for mummy model) and the body area lying on the floor (38\%), compressing the filling and the remainder insulated by the uncompressed filling.

For a blanket model bag:

$$
I_{T}=\frac{1}{\left(\frac{0.57}{I_{u p}}+\frac{0.36}{I_{\text {down }}+I_{\text {mat }}}+\cdot \frac{0.07}{I_{\text {face }}}\right)}=\frac{1}{\left(\frac{0.57}{20 \cdot d_{u p}}+\frac{0.36}{30 \cdot d_{\text {down }}+I_{\text {mat }}}+\cdot \frac{0.07}{I_{\text {face }}}\right)}
$$

for a mummy bag:

$$
I_{T}=\frac{1}{\left(\frac{0.61}{I_{\text {up }}}+\frac{0.36}{I_{\text {down }}+I_{\text {mat }}}+\cdot \frac{0.03}{I_{\text {face }}}\right)}=\frac{1}{\left(\frac{0.61}{20 \cdot d_{\text {up }}}+\frac{0.36}{30 \cdot d_{\text {down }}+I_{\text {mat }}}+. \frac{0.03}{I_{\text {face }}}\right)}
$$

With $I=$ insulation (in $\mathrm{m}^{2} . \mathrm{K} \mathrm{W}^{-1}$ ), $d=$ thickness (in $\mathrm{m}$ ) and $l_{\text {face }}=0.105 \mathrm{~m}^{2} . \mathrm{K} \cdot \mathrm{W}^{-1}$

A second order approximation is then to measure the actual insulations uncompressed and compressed on a flat plate and use the measured numbers in equations [12] and [13], rather than the thicknesses.

\subsubsection{Manikin measurement}

Manikins can be used to measure sleeping bag insulation. ISO 13537 (2002) describes such a measurement and defines the use of 'a rigid support (12 $\mathrm{mm}$ wood board)' to simulate the ground, with air passing underneath; 'a mat, representative of the user group' and 'a two piece track suit and knee-long socks' as clothing. Given the large impact of the mat, representing more insulation towards the floor than the actual underside of the bag in many cases, this is an important factor to specify and keep constant in comparisons.

Based on the heat resistance measurement they specify that a utility range shall be reported, including a comfort, a limit and an extreme temperature.

A problem with many manikins for sleeping bag measurements is that their weight is much lower than that of a human being, causing too little compression of the filling underneath the person. Hence, these manikins would need to be weighed down for the test.

\subsubsection{Human subject testing}

Similar to the insulation testing of clothing with human participants, this can also be done for sleeping bags (Havenith et al., 1989) by measuring heat production and heat losses, or by trialling bags at different temperatures and asking for subjective feedback. In general, it is the temperatures of the feet and toes that when measured provide the most sensitive discrimination between different bags. Once a person cools, feet cool fastest and are most sensitive to the insulation provided (Havenith, 1989). 


\subsubsection{Minimal temperature for sleep}

After determining the insulation of a bag there often is a need to estimate the minimal temperature for sleep. Numerous models have been produced for this, with a variety of assumptions.

A simple first order calculation is provided by (Havenith, 1994):

$$
T_{a, \text { min }}=33-\frac{70 \cdot I_{T}}{1.8}=33-39 \cdot I_{T}
$$

Assuming a mean skin temperature of $33^{\circ} \mathrm{C}$ and a heat production of the body of 70 watts with a $1.8 \mathrm{~m}^{2}$ body surface area $\left(38.9 \mathrm{~W} \cdot \mathrm{m}^{-2}\right)$. These calculations, given the low heat production while asleep, are highly sensitive to the estimation of that heat production. Several authors have therefore also done calculations where they 'accept' a certain amount of body cooling within a certain period of sleep. Some examples of calculations:

Steady state comfort sleep:

$$
\begin{gathered}
T_{a, \min }=32-34.8 \cdot I_{T} \quad \text { (Goldman, 1988) } \\
T_{a, \text { min }}=32.8-31.1 \cdot I_{T} \quad \text { (McCullough, 1994) }
\end{gathered}
$$

For limited time sleep with some cooling:

$$
\begin{gathered}
T_{a, \min }=32-43.2 \cdot I_{T} \quad(6 \text { hours; Goldman, 1988) } \\
T_{a, \min }=31.4-37.3 \cdot I_{T} \quad \text { (8 hours; McCullough, 1994) }
\end{gathered}
$$

In contrast to these simple calculations, the ISO standard model contains a higher number of assumptions, regarding the user's posture, gender etc. A table of sleep temperature limits in relation to measured insulations is provided in the standard.

\section{Future trends}

A number of developments in lab testing are anticipated. In the area of manikin development, the sweating features will become more detailed, and with emerging knowledge on whole body sweat patterns (Havenith et al. 2008, Machada-Moreira et al. 2008), manikins are expected to show differentiated sweating over different zones. Though this may not be relevant to the general determination of ensemble vapour resistances, given the introduction of more sources of uncertainty and error by this method, it will enable comparison of garment systems by going through various realistic scenarios for climate, work load and associated physiological responses (i.e. sweat production).

The other major development is expected in the area of assessment of smart clothing. New methods need to be developed to assess the real world value of smart clothing with conditions representative for actual work situations. 


\section{References}

ASTM D7024 (2004) 'Standard test method for steady state and dynamic thermal performance of textile materials', American Society for Testing Materials.

ASTM F1291 (2005) 'Standard test method for Measuring the thermal insulation of clothing using a heated manikin', American Society for Testing Materials.

ASTM D1518 - 85 (2003) 'Standard Test Method for Thermal Transmittance of Textile', American Society for Testing Materials.

ASTM F1868 - 02 (2002) 'Standard Test Method for Thermal and Evaporative Resistance of Clothing Materials Using a Sweating Hot Plate', American Society for Testing Materials.

ASTM F2370 (2005) 'Standard test method for Measuring the evaporative resistance of clothing using a sweating manikin', American Society for Testing Materials.

ASTM E96 / E96M - 05 (2005) 'Standard Test Methods for Water Vapor Transmission of Materials', American Society for Testing Materials.

ASTM F2298 (2003) 'Standard Test Methods for Water Vapor Diffusion Resistance and Air Flow Resistance of Clothing Materials Using the Dynamic Moisture Permeation Cell', in "Annual Book of ASTM Standards 11.03", American Society for Testing and Materials, West Conshohocken, PA.

Behman F W (1988) Chapter 16; 'Field evaluation methods'. In: Handbook on clothing RSG 7, Panel VIII, Nato. (available at www.environmental-ergonomics.org)

Birnbaum R R and Crockford G W (1978) 'Measurement of the clothing ventilation index', Applied Ergonomics 9(4), 194-200.

Bo-an Y, Kwok Y L, Li Y, Yeung C Y, Song Q (2004) 'Thermal regulating functional performance of PCM garments', International Journal of Clothing Science and Technology ISSN: 0955-6222 Volume: 16 Issue: 1/2 Page: 84 - 96. DOI: 10.1108/09556220410520388.

Bo-an Y, Kwok Y, Li Y, Zhu Q and Yung C (2005) 'Assessing the performance of textiles incorporating phase change materials', Polymer TestingVolume 23, Issue 5, Pages 541-549.

BS 7209 (1990) 'Specification for water vapour permeable apparel fabrics leakage, British Standards Institute, London'.

BS 3424-18 (1986) 'Testing coated fabrics. Methods 21A and 21B. Methods for determination of resistance to wicking and lateral leakage', British Standards Institute, London.

BS 4745 (2005) 'Determination of the thermal resistance of textiles. Two-plate method: fixed pressure procedure, two-plate plate method: fixed opening procedure, and singleplate method', British Standards Institute, London. 
CAN/CGSB-4.2 No. 49 - 99 (1999), 'Textile Test Methods Resistance of Materials to Water Vapour Diffusion', Canadian General Standards Board

CAN/CGSB 4.2 NO. 70.1-94 (1994) [withdrawn] 'Textile Test Methods - Thermal Insulation Performance of Textile Materials', Canadian General Standards Board

CAN/CGSB 4.2 NO. 78.1-2001 (2001) 'Textile Test Methods - Thermal Protective Performance of Material for Clothing', Canadian General Standards Board

Daanen H A M, Hatcher K and Havenith G (2002) 'Determination of Clothing Microclimate Volume', Environmental Ergonomics $X$, The Organizing and International Program Committees of the 10th International Conference on Environmental Ergonomics (eds), The 10th International Conference on Environmental Ergonomics , Fukuoka, Japan, 66-5668, ISBN 4990135806.

DIN 53924 (1997) '-03 Prüfung von Textilien - Bestimmung der Sauggeschwindigkeit von textilen Flächengebilden gegenüber Wasser (Steighöhenverfahren)', German Standardisation Institute, Berlin.

Dorman L, Havenith G (2009) 'The Effects Of Protective Clothing On Metabolic Rate', European Journal of Applied Physiology, 2009, (in press).

Dorman L, Havenith G, Brode P, Candas V, den Hartog E, Holmer I, Meinander H, Nocker W and Richards M (2006) 'Modelling the Metabolic Effects of Protective Clothing', Central Institute for Labour Protection - National Research Institute, 3rd European Conference on Protective Clothing (ECPC), Poland, ISBN: 83-7373-097-4.

EN 13537 (2002) 'Requirements for sleeping bags', European committee for standardization, Brussels.

EN 14058 (2004) 'Protective clothing. Garments for protection against cool environments', European committee for standardization, Brussels.

EN 14360 (2004) 'Protective clothing against rain. Test method for ready made garments, Impact from above with high energy droplets', European committee for standardization, Brussels.

EN 20811 (1992), ISO 811 (1981) 'Textiles. Determination of resistance to water penetration. Hydrostatic pressure test', European committee for standardization, Brussels; International Organisation for Standardisation, Geneva.

EN 342 (2004) 'Protective clothing. Ensembles and garments for protection against cold', European committee for standardization, Brussels.

EN 511 (2006) 'Protective gloves against cold', European committee for standardization, Brussels.

EN ISO 11079 (2007) 'Ergonomics of the thermal environment. Determination and interpretation of cold stress when using required clothing insulation (IREQ) and local cooling effects', International Organisation for Standardisation, Geneva. 
EN ISO 15831 (2004) 'Clothing. Physiological effects. Measurement of thermal insulation by means of a thermal manikin', International Organisation for Standardisation, Geneva.

EN ISO 9237 (1995) 'Textiles. Determination of the permeability of fabrics to air', International Organisation for Standardisation, Geneva.

EN ISO 9920 (2007) 'Ergonomics of the thermal environment. Estimation of thermal insulation and water vapour resistance of a clothing ensemble', International Organisation for Standardisation, Geneva.

Goldman R F (1974) 'Clothing design for comfort and work performance in extreme thermal environments'. Transactions of the new york academy of sciences series ii vol 36 (6).

Goldman R F (1988) In: Handbook on clothing RSG 7, Panel VIII, Nato. (available at www.environmental-ergonomics.org).

Havenith G and Heus R (2004) 'An ergonomic test battery of protective clothing', Applied Ergonomics, 35/1 pp. 3-20.

Havenith $\mathrm{G}$ and Nilsson $\mathrm{H}$ (2004) 'Correction of clothing insulation for movement and wind effects, a meta-analysis', Eur J Appl Physiol (2004) 92: 636-640: http://springerlink. metapress.com/link.asp?id=95rc2htfa29nphkp.

Havenith $\mathrm{G}$ and Nilsson $\mathrm{H}$ (2005) 'Correction of clothing insulation for movement and wind effects, a meta-analysis', Eur J Appl Physiol (2005) 93: 506 Erratum to previous publication.

Havenith G, den Hartog E and Heus R (2004) 'Moisture Accumulation in Sleeping Bags at 7 and $-20^{\circ} \mathrm{C}$ in Relation to Cover Material and Method of Use', Ergonomics, vol. 47, 13 , 1424-1431.

Havenith G (1994) 'Classification for sleeping bags model "mummy" (in Dutch)', Report TNO-TM 1994 C-33, TNO Human Factors Research Institute, Soesterberg.

Havenith G (2002) 'Moisture Accumulation in Sleeping Bags at Sub-Zero Temperature; Effect of Semipermeable and Impermeable Covers', Textile Research Journal, 72(4), 281-284.

Havenith G (2002) 'Clothing and Thermoregulation', Allergologie , 25(3) , 177, ISSN 0344 5062.

Havenith G and Dorman L (2007) 'Race to the South Pole - Scott and Amundsen's clothing revisited', Proceedings of the 12th International Conference on Environmental Ergonomics, Igor B. Mekjavic, Stelios N. Kounalakis, Nigel A.S. Taylor, Biomed, Piran, Slovenia, August 2007, pp 150-152, ISBN 978-961-90545-1.

Havenith G and Heus R (1989) 'Insulation, comfort and moisture accumulation of six prototypes of sleeping bags for the Royal Netherlands Army' (in Dutch). Report IZF 1989-40, TNO Institute for Perception, Soesterberg.

Havenith G, Fogarty A, Bartlett R, Smith C and Ventenat V (2008a) Male and female upper body sweat distribution during running measured with technical absorbents. 
European Journal of Applied Physiolog,.104(2) 245- 255

http://dx.doi.org/10.1007/s00421-007-0636-z

Havenith G, Heus R, Lotens W A (1990) 'Clothing ventilation, vapour resistance and permeability index: changes due to posture, movement and wind' Ergonomics 33/8, 989-1005.

Havenith G, Richards M, Wang X, Broede P, Candas V, den Hartog E, Holmer I, Kuklane K, Meinander $\mathrm{H}$ and Nocker W, (2008b) 'Apparent latent heat of evaporation from clothing: attenuation and "heat pipe" effects"', J Appl Physiol, Jan 2008; 104: 142 149.

Havenith G, Ueda H, Sari H and Inoue Y (2003) 'Required clothing ventilation for different body regions in relation to local sweat rates' Proceedings 2nd European Conference on Protective Clothing (ECPC), "Challenges for Protective Clothing" 21 - 24 May 2003, Montreux, Switzerland.

Holmér I and Elnas S (1981) 'Physiological evaluation of the resistance to evaporate heat transfer by clothing' Ergonomics, 24, 63-74.

Huang J and Qian X (2008) 'Comparison of Test Methods for Measuring Water Vapor Permeability of Fabrics'. Textile Research Journal, vol. 78: pp. 342 -352.

ISO 11092 (1993); EN 31092 (1994) 'Textiles. Determination of physiological properties. Measurement of thermal and water-vapour resistance under steady-state conditions (sweating guarded-hotplate test)', International Organisation for Standardisation, Geneva; European committee for standardization, Brussels.

Kuklane K, Afanasieva R, Burmistrova O, Bessonova N and Holmér I (1999) 'Determination of heat loss from the feet and insulation of the footwear', Int J Occup Saf Ergon. 1999;5(4):465-76.

Kuklane K, Nilsson H, Holmér I and Liu X (1997) 'Methods for handwear, footwear and headgear evaluation', Nilsson H \& Holmér I eds. Proceedings of a European Seminar on Thermal Manikin Testing, Arbetslivsrapport 1997:9, Solna, Sweden.

Lotens W A (1993) 'Heat Transfer from Humans Wearing Clothing', PhD Thesis Technische Universiteit Delft.

Lotens W A and Havenith G (1988) 'Ventilation of rainwear determined by a trace gas method'. In: Environmental Ergonomics. Mekjavics, Bannister, Morrison Eds., Taylor and Francis, Philadelphia, p. 162-175.

Lotens W A and van de Linde F J G (1982) 'A comparison of three firefighter suits,Part II: Ergonomics and practice tests (Een vergelijking van drie brandweerpakken II: Ergonomie en praktijkproeven.)' Report Institute for Perception IZF 1982 C-14.

Lotens W A (1988) 'Optimal design principles for clothing systems', Handbook on clothing RSG-7 (Nato) (Chapter 17).

McCullough E A (1994) 'Determination of the insulation value and temperature rating of sleeping bags', Proc. Outdoor retailer coalition, Reno, NV, August 20. 
McCullough, E. A., Kwon, M., and Shim, H., (2003) A Comparison of Standard Methods for Measuring Water Vapour Permeability of Fabrics, Meas. Sd. Technol., 14(8), 14021408.

Mecheels J, Umbach K H (1976) 'Thermophysiologische Eigenschaften von Kleidungssystemen (Thermophysiological properties of clothing systems)' Melliand Textilberichte vol 57 part 12 1029-1032.

Machado-Moreira C A, Smith F M, van den Heuvel A M J, Mekjavic I B, Taylor N A S (2007) 'Sweat secretion from the torso during passively-induce and exercise-related hyperthermia', Eur J Appl Physiol 104(2) 265-270; doi: 10.1007/s00421-007-0646-x

Pause B H (2000) 'New Heat Protective Garment with Phase Change Material' , Performance of Protective Clothing: Issues and Priorities for the 21st Century: Seventh Volume, ASTM STP 1386, 2000.

Reinertsen R E, Faerevik H, Holbo K, Nesbakken R, Reitan J, Royset A and Thi M S (2008) 'Optimising the performance of phase change materials in personal protective clothing systems', International Journal of Occupational Safety and Ergonomics, in press.

Rintamäki H and Rissanen S (2006) 'Heat strain in the cold', Industrial Health Vol. 44 No. 3 427-432.

Shim H, McCullough EA (2000) 'The effectiveness of phase change materials in outdoor clothing', Ergonomics of Protective Clothing,Proceedings of nokobetef 6 and 1st European Conference on Protective Clothing held in Stockholm, Sweden, May 7-10, 2000.

Ueda H and Havenith G (2002) 'The Effect of Fabric Air Permeability on Clothing Ventilation' Environmental Ergonomics $X$, The Organizing and International Program Committees of the 10th International Conference on Environmental Ergonomics (Eds), 10th international Conference on Environmental Ergonomics , Fukuoka, Japan, September 2002, 621-624, ISBN 4990135806.

Ueda H, Inoue Y, Matsudaira M, Araki T and Havenith G (2006) 'Regional microclimate humidity of clothing during light work as a result of the interaction between local sweat production and ventilation', International Journal of Clothing Science and Technology, 18-4. 225-234.

Umbach (1983) 'Evaluation of comfort characteristics of clothing by use of laboratory measurements and predictive calculations', Research Inst. of National Defence Intern. Conf. on Protective Clothing Systems (SEE N83 2645415 54); Sweden;: 141-149.

Van Langenhove L and Kiekens P (2001) 'Textiles and the transport of moisture', Textile Asia 32-43.

Wissler E.H. and Havenith G. (2009) 'A Simple Theoretical Model of Heat and Moisture Transport in Multi-layer Garments in Cool Ambient Air', submitted to European Journal of Applied Physiology. 


\section{List of Captions}

Fig. 1, six stages in the development and assessment of clothing systems (modified from Goldman, 1976 and Umbach, 1983)

Fig. 2, schematic drawing of a sweating guarded hot plate according to ISO 11092.

Fig. 3, Example of a thermal manikin (model type 'Newton', MTNW, Seattle)

Fig. 4, pathways for heat loss through clothing (used with permission from JAP, Havenith, 2008b)

Fig. 5 Increase in energy consumption due to wearing protective clothing versus a track suit control for clothing as worn by Robert Falcon Scott and Roald Amundsen on their expedition to the South Pole in 1911-12, and for modern expedition type clothing (Havenith and Dorman, 2007). Values for different activities: sledge pulling (Scott team) and dog sledge travel (Amundsen team).

Fig. 6, Heat resistance of insulative fabrics and battings in relation to their thickness (redrawn from Havenith et al. 2002)

Fig. 7, thickness of sleeping bags measured at 20 and $1500 \mathrm{~Pa}$, in relation to the number of washing cycles performed (Havenith, unpublished data). 


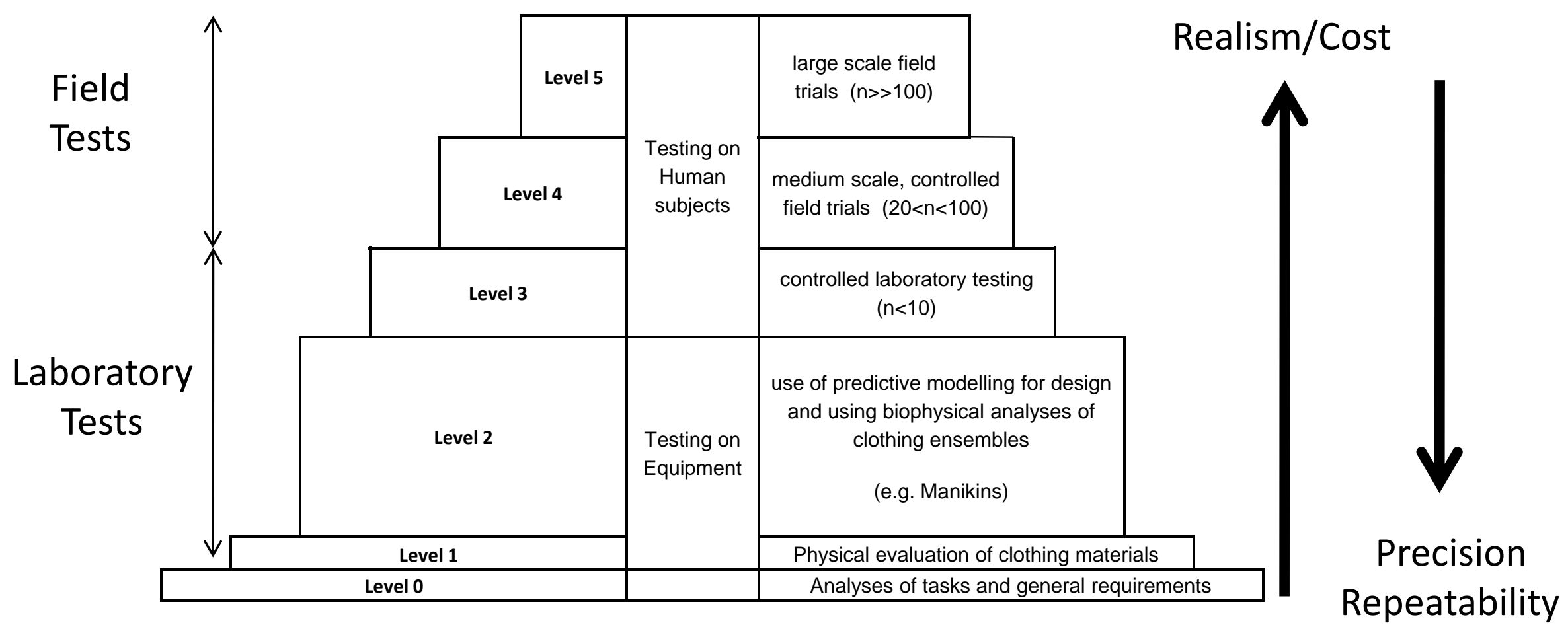




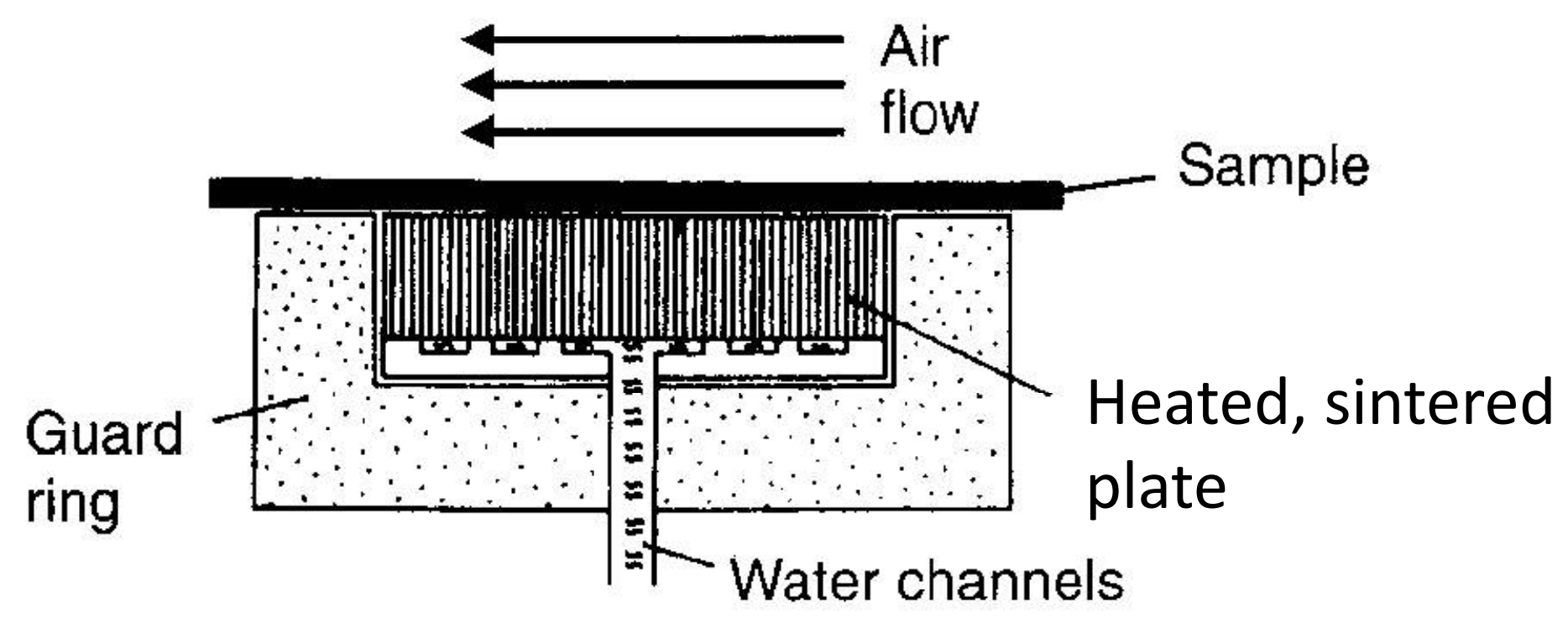




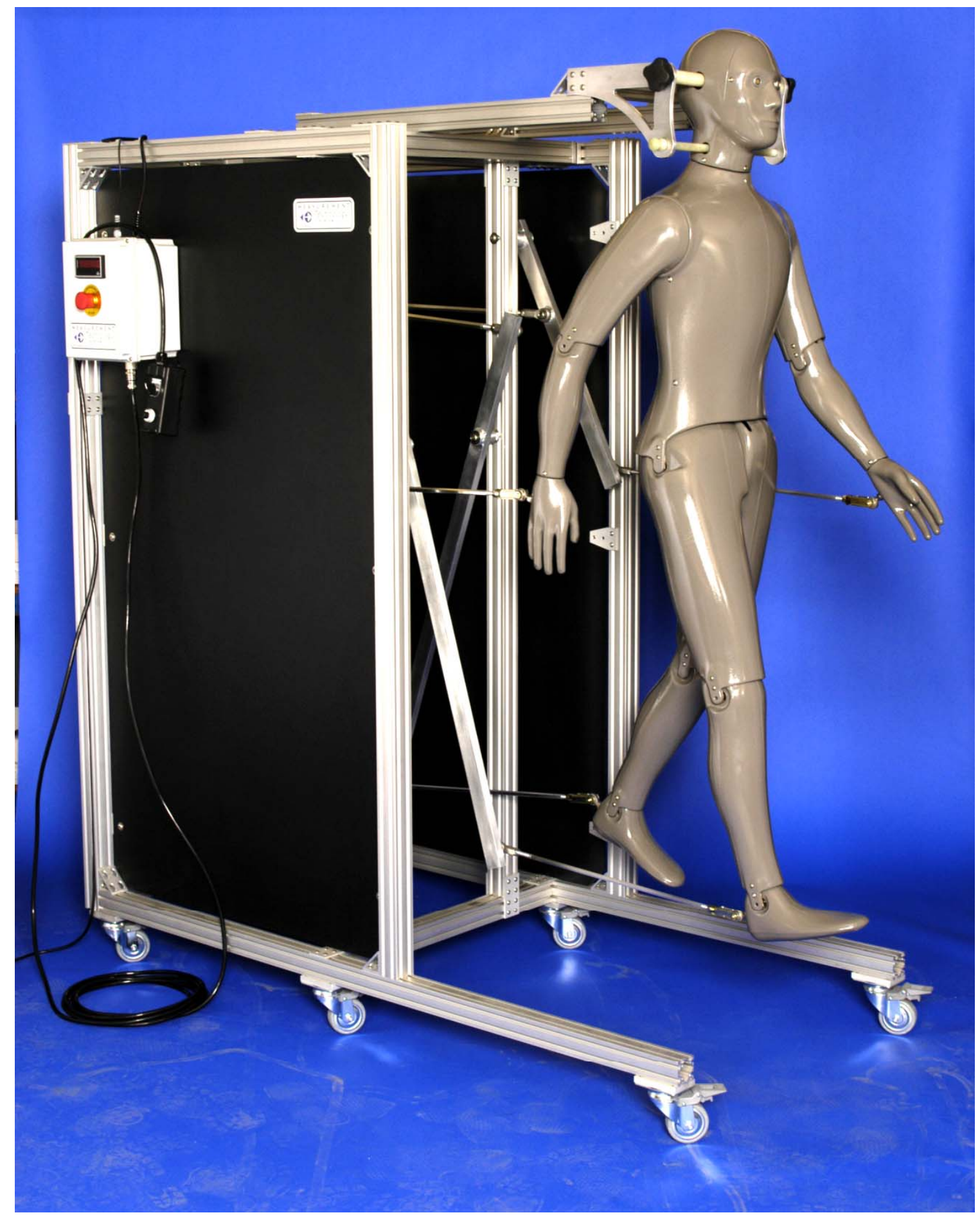




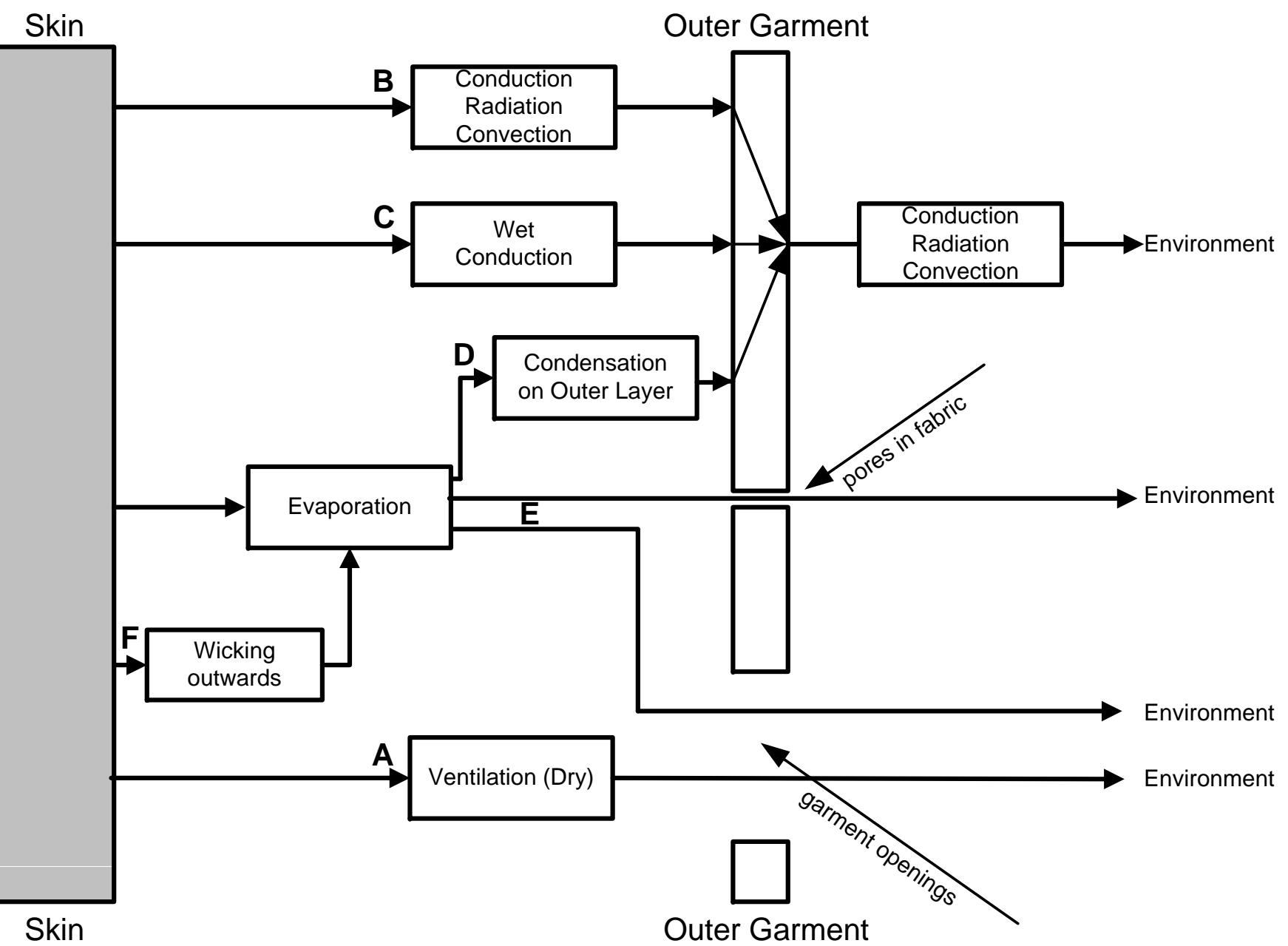




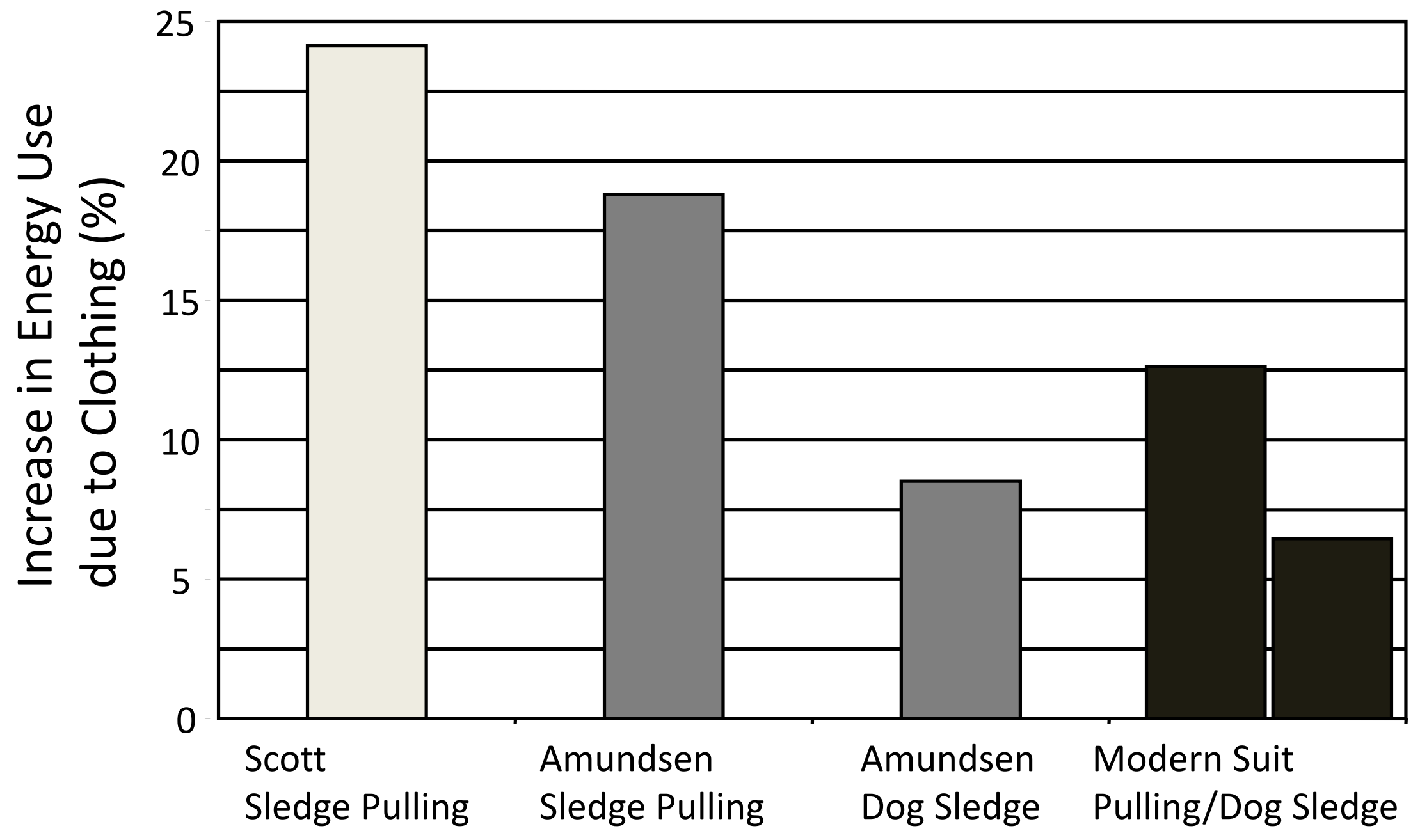




\section{Clothing materials, Insulation}

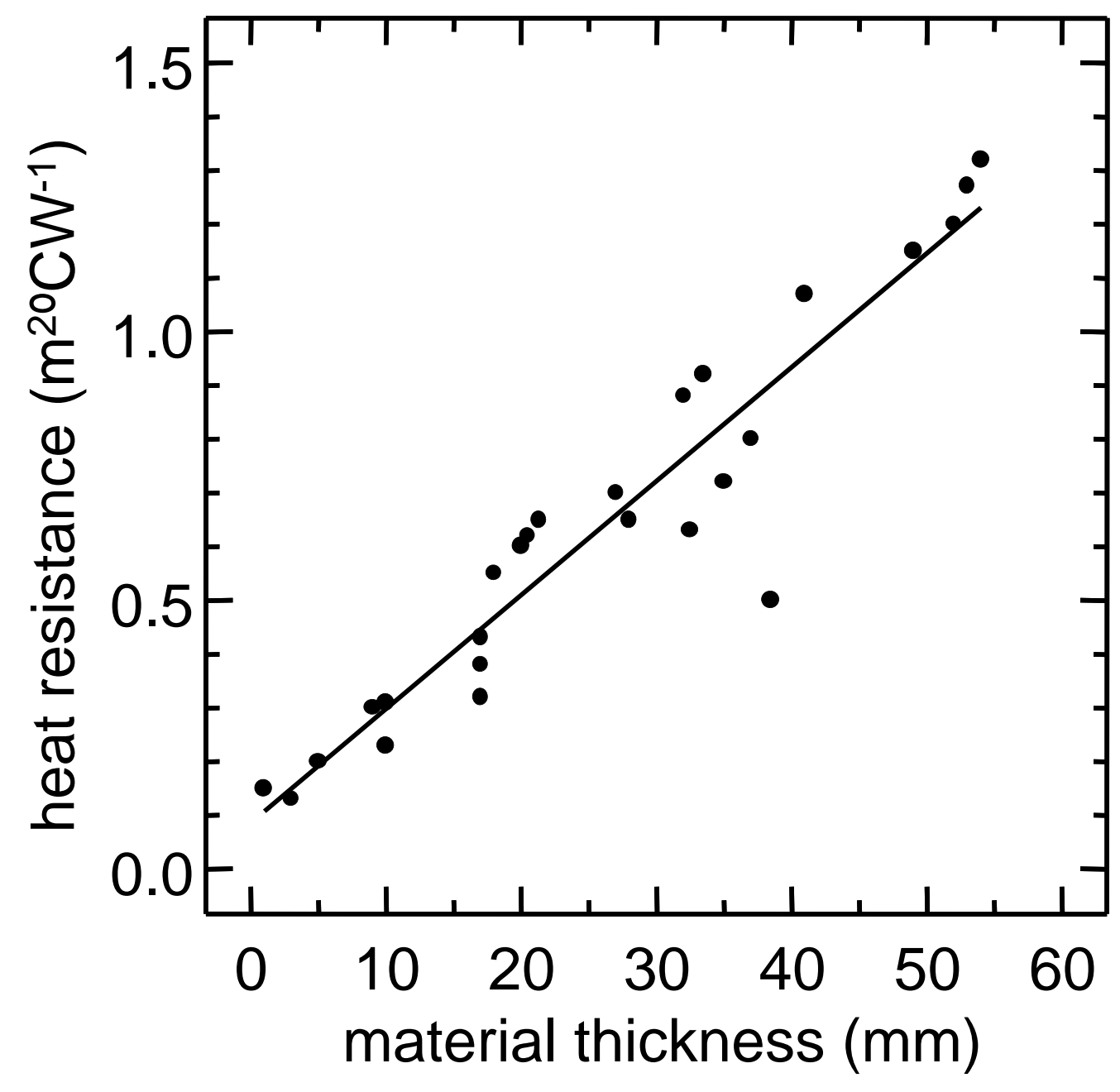






